\title{
Characterization of structure and expression of the growth hormone receptor gene of the Japanese flounder (Paralichtys olivaceus)
}

\author{
Nobuhiro Nakao ${ }^{1}$, Yoshifumi Higashimoto ${ }^{1}$, Takeshi Ohkubo², \\ Hideo Yoshizato ${ }^{3}$, Naoya Nakai ${ }^{1}$, Kunio Nakashima ${ }^{1}$ and \\ Minoru Tanaka ${ }^{4}$ \\ ${ }^{1}$ Department of Biochemistry, Faculty of Medicine, Mie University, Tsu, Mie 514-8507, Japan \\ 2 Faculty of Agriculture, Kagawa University, Miki, Kagawa 761-0795, Japan \\ ${ }^{3}$ Department of Bioscience, Nagoya Institute of Technology, Nagoya 466-8555, Japan \\ ${ }^{4}$ Department of Animal Science, Faculty of Applied Life Science, Nippon Veterinary and Animal Science University, Musashino, Tokyo 180-8602, Japan \\ (Requests for offprints should be addressed to M Tanaka; Email: mitanaka@nvau.ac.jp)
}

\begin{abstract}
Growth hormone receptor (GHR) cDNA and gene of the Japanese flounder (Paralicthys olivaceus) were cloned and their molecular structures were characterized. The 641 amino acid sequence predicted from the cDNA sequence showed more than $75 \%$ overall sequence similarity with GHRs of other teleosts such as turbot and goldfish, and contained common structural features of vertebrate GHRs. The extracellular domain of flounder GHR had three pairs of cysteines and an FGEFS motif with a replacement $\mathrm{E}$ to $\mathrm{D}$. The cytoplasmic domain contained two conserved motifs referred to as box 1 and box 2 . The flounder GHR gene was cloned by PCR using primers designed from the sequence of the GHR cDNA. The GHR gene was composed of 10 exons. The sequence of exon 1 corresponded to the $5^{\prime}$-untranslated region of the cDNA, and exons 2-6 encoded most parts of the extracellular domain. The transmembrane domain was found in exon 7 , and the intracellular domain was encoded in exons 8-10. Exon 10 also encoded the 3'-untranslated region. Comparison of the flounder GHR gene with the human
\end{abstract}

GHR gene shows that the flounder gene contains no exons corresponding to exon 3 of the human GHR gene, and that the region corresponding to exon 10 in the human GHR gene is encoded by exons 9 and 10 in the flounder GHR gene. These findings indicate that the flounder GHR gene diverged from those of mammalian and avian GHR genes, especially in the organization of the exons encoding the cytoplasmic domain. In addition to the regular form of GHR mRNA, a 3'-truncated form lacking the region derived from exons 9 and 10 was detected as a minor species in the liver by RT-PCR and by RNase protection assay. RT-PCR analysis showed that both the regular and the $3^{\prime}$-truncated GHR mRNAs are expressed in a wide range of flounder tissues with the highest levels being found in the liver. The $5^{\prime}$-flanking region of the flounder GHR gene was cloned by inverse PCR, and three transcription start points were identified with similar frequency by RNase protection assay.

Journal of Endocrinology (2004) 182, 157-164

\section{Introduction}

Growth hormone $(\mathrm{GH})$ plays an essential role in the postnatal growth of vertebrates. The growth promoting effect of $\mathrm{GH}$ is mediated by insulin-like growth factor I (IGF-I) mainly synthesized in the liver (Mathews et al. 1986, Roberts et al. 1986). In addition to growth promotion, GH also has well-recognized metabolic/ glucoregulatory actions. These functions of GH are exhibited through $\mathrm{GH}$ receptors (GHRs) in target tissues. The GHR is a member of the cytokine/hematopoietin receptor super family containing several common structural features (Kelly et al. 1991, Kopchick \& Andry 2000). The extracellular domain of this family member contains several pairs of cysteines and a WSXWS motif which is substituted to a YGEFS motif in GHR. In the extracellular domain, there are two conserved regions referred to as box 1 and box 2 which are known to be essential for the signal transduction pathway composed of the Janus kinases (Jak) family and the signal transducer and activation of transcription (STAT) family.

The GHR gene has been extensively characterized in human and mouse. The human GHR gene is composed of 10 exons with at least nine first exons (V1-V9) which 


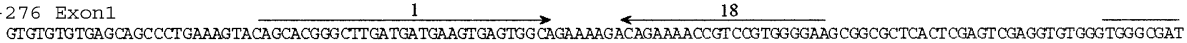

$\frac{19}{\text { GT GAACAAATCCT GCTCGGATCAGATCTTGTTTCGGGGCCGAGCAGCAGGCTCGAGGTGAGGGAGCAGGACTTTTCCGAGCCTGTCGGTGCTCACGCTGGACAT CAGATGACCAACTTCT }}$

GAAAAGTCGATCCGCTCGAGACATCACAACARgtgagtggtg-.......... $9 \mathrm{~kb}$..........-. ctgtct ccagCATCATGGCTGTCTCCTCACCCTCCTCTCACCTCCTGATCCT

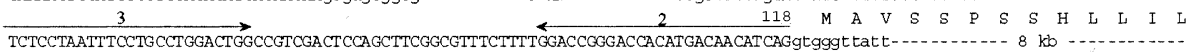

L L I S C C L D W 119 Exon 3

3

tgtct tt tagCTCCCACT GAGCCTCATTTCACTGAATGCATCTCCAGGGAGCAGGAGACATTTCGCTGTTGGTGGAGTCCAGGCACCTTCCAGAACCTGTCCTCCCCTGGAGTACTCCGA

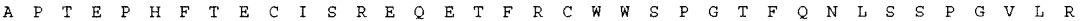

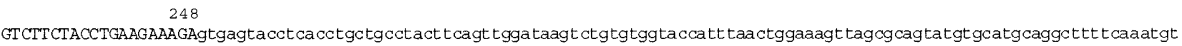

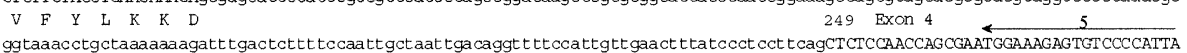
ggtaaacctgctaaaaaaagatt tgactcttt tccaattgctaat tga caggtt ttccattgttgaact ttatccetcct tcagCTCTCCAACCAGCGAATGGAAAGAGTGTCCCCATTA
S P T S E W K E C P H Y TAACTATTCAAACAGGGAATGTTTCTTCGACGTGAACCACACATCTATTTGGATCCCCTACTGCATGCAGCTGCGCAGCCAAAACGCCACCTTTATTAATGAGGACGATTGTTTCACAGT

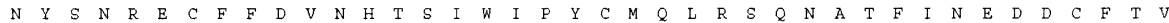
415

GGAAAATATTGgtaagttatcagcact tgtgcatatcctgat ccaatgaactaggact $t$ cttcactatatttccagt ggttttaagagtgt gaagcatggtatagcatgatagatcacct E N I

ctacaagtttccaggaaa cggtatttgctgctgtatatcaaa tcagcaaatgt cacatgcttgt cagcatcacagcaggtgttaaatacacagtggttacacgctaaatgtt $t$ tga tgtc tgatggtatttatctaat caggactgtagaagataatgatagacgctgtattatcacatgttaatgtcatgtgtttgctgatatttcttccctggaaaa tgtgt tgaat tgagtgtcage atggttgttgtatagataaca tatggttgttgtcctcagtacacataggaataaagaatgacatgaa tcattggctctgtaggctgtcccagagaaaatat ctcttcagctgttggtggc ttctcctggaagt ttgct tatgtttttattggtcaccatatgagaagctctatt taat $\operatorname{cct} t c t a a a t c t t g c a c t a c c a t c a a g g a a a c a t a g g g c t a a c a c t a t a g t g a g t a c t a g c$ aaagcccattttcacattatatatttaatacataataacaagagt tgt ct ttatctaactataattctt tat ttgttcagccattgatgtatttgccatgt tgagtggtattaatagct 416 Exon 5

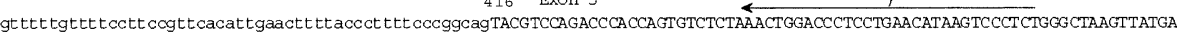

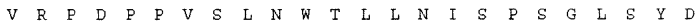
8 TGTCATGGTCAACTGGGAGCCCCCGCCCTCTGCAGACGTCGCGGCGGGCTGGATGCGCCTTGAGTATAAAATCCAGCACAGAGAGAGAAATGCCACAAACTGGAAATCAgtgagtgttCt

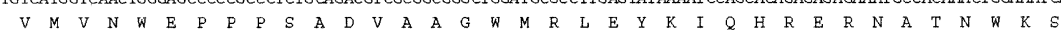
ctctttataattgctcttaaactctctctctctctcttcctt cctttgccttgaggcagacactggtacgtgagcatgtaaacacacacct taaaacttaa caaaaaagtctctgtgcat acacgtaagctcacaccaacgcaaaca cgtatgcacgctcttaaaagtaaattgtaggtaggtcatagtggcacagtgtcgtgtttccttccccctcccccaaggagtctcatggctaaa atgcagtgtagctttgttggcaaggcgatggaagccagagcaaggtcctctgggaaat cacagcctctctgaaggaagtgaagggagggat ctgtaggt cagaggccat gggacct tgtg caggctcctattcat tac cgtgtggccaatcgtctgatgaatgcagccttggaaactat tctagaacct tccat tataacagt cct tgg cctaatgtat ccaaaatgacaaaataacaat cg cctatggaaaggcaacagt tataaacat ct taa caccttgttcagcttagtttagcttcagctgttttctaat caatcaaaacat tgcaaaatcactttattctctctctat tctc 595 Exon 6 $9 \underset{9}{\stackrel{10}{\longrightarrow}}$ tgttt tcattctctccggtgtgt ttctatattgcagTTGGCAACTCAGCCGCACACTCACCAGGGAATCTACGGTCTGCACATAGGCAAACAGTATGAAGTGCAGATCAGCTGCAGGATG L CAGGCCTTCACTAAGTTTGGAGACTTTAGTGACTCTATCTTCATTCACGTGACTGAGATTCTCAGTGGAGgtaaagtcaacttgactcaagggtggaatgttaaatctgttggtcagatg

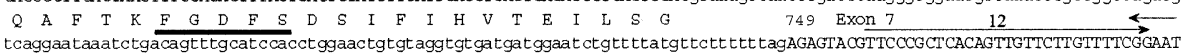
tcaggaataaatctgacagtttgcatccacctggaactgtgtaggtgtgatgatggaatctgttttatgttctt ttt tagAGAGTACGTTCCCGCTCACAGTTGTTCTTGTTTTCGGAAT
11
839 CGTGGGCATCCTCATACTCATCATGCTGATTGTCGTCTCTCAGCAGCACAGgtaggaa cagt tacactctctctcttttatacacattcaaccaacact gtccaaaacacactggacct9 $V$ G I L I L

ctgaagcatgatggcagtgataacatgtgaaatgtttgctaaatcagcagcagattetgcagcgcacttctctgcaaggacacacacacacacacacacacacatacacatacacacaca cgcacgctgacaaatatgataaacagattatctt cat catgttttctcatcttgctgcctttacagATTCATGA TAATTATTTTACCACCAGTTCCTGCACCCAAAATTAAAGGCATTGA

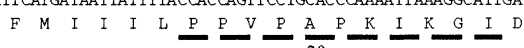
TCCAGAC 909

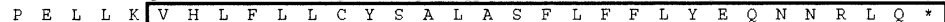

ctetcgtgtcacagatatatggtttct gctttctatgtcgtcaagagaagaaat tgtagtagtgaatatgccatatatttgaggtaatttgaaaaaaaaggtcatgcat tcatgat ttat

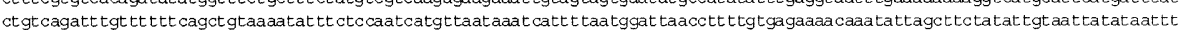
caattatctaaaa ta cactgtgggagtatttcttgggtactggatgtgcttaaangggttaattggtaacat caattaat tcacaggcggt aacatgtggaactggtggcttgcttattc cagaaaagtggtggggtaaccactgggtttttttggat cc $c$ t tacaaggtaat $c t$ tggattggaaaccggacaaccctggaacattcccgtgggaa cat taaggccaca caatcatccca ccaacacccaccgtccttntcccaact ngctggttgt caaccaatgaaat tmaaggmnnaaaatgt ccataaccaatttgaagccaaagcaccacact ttt tnttgtttttettaagto caaccaaggaccaggaga ccactgagggataataacacgtgaagaggt tegtggttcagcat tgtgctgtgggatgcatt tataagacagc cctggacctcagaacaaaaagtgct tgta tgaat aatgaaatgaaaa tgctgctat ttcat aattagacaaaggtggaaacacaatgcttgatttgcagctgatactgtgcagcgaat acaaatagat ctgttttgcttcctgat cacg 910 Exon 9

acacacgcctgatat ttgtacaaatttgtgcatt tgcagAAGGGGAGGCTGGACGACCT GAATTTGATCCTGAGTGGTGGAGGTATGGGCGGCCTGTCCACCTATGCACCAGATTT CTAC

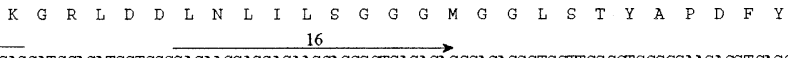
CAAGATGAGCCATGGGTTGAGTT CATCGACGTGAATGCTGAGGATGCAGATGCTGGGGAGAAGGAGGACAACCAGGGCTCAGACACCCAGAGGCTCCTTGGCCTGCCCCAACACGTCAGC

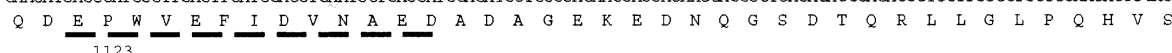
CACCACATGAACAgtggatgctccaacaccattgggtactgcaaagattcttatgtgaaggetgtggtttcacgaaaacaaatgtctttgcattatgaatttcatccatttttccctctg H H M N 1124 Exon 10

tttccctctgcat cagct tccctgatgatgactcaggcagGTGGATGCTCCAACACCATTGGCTTCCCTGATGATGACTCAGGCAGGGCCAGCTGTTACGACCCAGATGTTCTCGACCAT S G $C$ C $S$ S N $N$ T I I G GACACCCTAATGATGATGGCCACTCTGTTGCCAGGCCAACCAGAGGATGAAGAAGCCTCCCTCGCTGTTGAAGAAGACTCCCTCGCTGTTGAAGAAGGAGTCTCAACCTCAGAGAGGACC D T L M M M A T T L L L P G Q

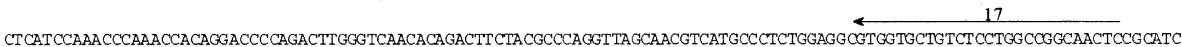

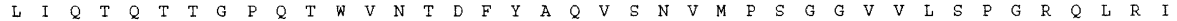
CAGGAGAGCACCTCAGCCACTGAGGAGGAAACACTGAAGAAAGGGAAAGAGGGCGAAGA CAACGAGGGGACCGCGGAGAAGAAGCAAAAAGAGCTG CAGTTTCACCTGCTGGTCG TGGAT Q E E S T $T$ S A CCOGAGGGAAGTGGCTACACCGCAGAGAGCACTGCCCGGCAAATCAGCACTCCCCCTTGCTCCCGCATGTCCGGTGAGGGGTACCAAACCATACACCCGCAGGCAGTGGAGACCAAACCT

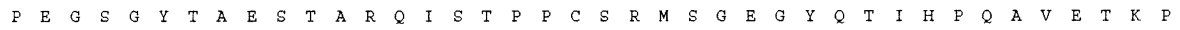
GCAGCCCCAGTAGAAGATAACCAATCATCTTATATTGTTCCTGACTCTCCCCAGTCCCAGTTCAGTGCTCCTGTTTCAGACTATACAGTGGTGCAGGAGGTGGA CACTCAGCACAGTCTG $\begin{array}{lllllllllllllllllllllllllllllllllllllllllll}A & A & P & V & E & D & N & Q & S & S & Y & I & V & P & D & S & P & Q & S & Q & F & S & A & P & V & S & D & Y & T & V & V & Q & E & V & D & T & Q & H & S & L\end{array}$ CTCCTCAACCCACCTCCCCGTCAGTCTCCCCCTCCCTGCCTGCCACAGCACCCCCTCAAGACCCTACCTGCTATGCCTGTAGGGTACATAACCCCAGACCTGCTGGGGAACCTCTCACCA

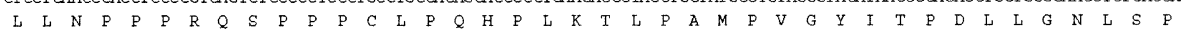
TGAAATGACAATGTGATTGGACCTAAGGGTGCAAGGTTGATTAACTAGGAAGTCCCCCATATTCACAAAAGCCTGTTTCGACCTAATTCCTGCTGGAAACCAAAAAACCTGTAGCACACA GTGTGATGAGCCTTTAAAGQ 
encode distinct 5 '-untranslated regions $\left(5^{\prime}\right.$-UTRs $)$ (Godowski et al. 1989, Pekhletsky et al. 1992, Zou et al. 1997, Goodyer et al. 2001). In the mouse GHR gene, four alternative first exons referred to as L1, L2, L3 and L5 have been identified and exons $2-10$ are homologous in size and sequence to those in the human GHR gene (Talamantes 1994, Menon et al. 1995, Moffat et al. 2000, Menon et al. 2001). In addition, the mouse GHR gene contains two extra exons (4B and 8A) which have no homologs in the human GHR gene (Edens et al. 1994, Zhou et al. 1994). Exon $4 \mathrm{~B}$ is located between exons 4 and 5 and encodes a unique amino acid sequence in the extracellular domain. In mouse and rat, GH-binding protein (GHBP) is generated by alternative splicing of the primary transcript of the GHR gene. The GHBP consists of a GH binding domain identical to that of the GHR and a unique hydrophilic domain at the C-terminal. In the mouse GHR gene, exon 8A encodes the unique C-terminal domain of the GHBP and the 3'-UTR of the GHBP mRNA (Zhou et al. 1994).

In non-mammalian species, the structural organization of the GHR gene has been reported only in chicken (Agarwal et al. 1994). The exon structure of the chicken GHR gene is similar to that of the human GHR gene except for the absence of the exon homologous to exon 3 of the human GHR gene. In fish, GHR cDNAs have recently been cloned and characterized in several teleost species such as turbot (Calduch-Giner et al. 2001), goldfish (Lee et al. 2001), and seabream (Tse et al. 2003). However, the genomic structure of fish GHR is not yet elucidated. In this paper, we report the characterization of the GHR gene of the flounder (Paralicthys olivaceus) for the first time in fish.

\section{Materials and Methods}

\section{Cloning of flounder GHR cDNA}

Total RNA was extracted from the liver of a 12-monthold female flounder with the ISOGEN kit (Nippon Gene, Toyama, Japan), and poly $\mathrm{A}^{+}$RNA was isolated with Oligotex-dT30 (TAKARA, Tokyo, Japan). A cDNA library was prepared from the RNA with the Marathon cDNA amplification kit (CLONTECH, Tokyo, Japan). A cDNA fragment of flounder GHR (fGHR) was amplified by 30 cycles of PCR with ExTaq polymerase (TAKARA). The PCR cycle consisted of $1 \mathrm{~min}$ at $94{ }^{\circ} \mathrm{C}, 2 \mathrm{~min}$ at $55^{\circ} \mathrm{C}$ and $3 \mathrm{~min}$ at $72{ }^{\circ} \mathrm{C}$. A sense primer $\left(5^{\prime}\right.$-AAACC
ACACGTCCATTTGGATCCCCTACTG-3') and an antisense primer $\left(5^{\prime}\right.$-GCCTTTAATTTTGGGTGCAG GAACTGGTGG-3') were designed from a conserved cysteine-rich region in the extracellular domain and the box-1 motif in the cytoplasmic domain of the reported turbot GHR cDNA respectively (Calduch-Giner et al. 2001). The amplified fragment of fGHR cDNA was cloned into pGEM-T Easy vector (Promega, Tokyo, Japan) and sequenced. The 5'- and 3'-regions of flounder GHR cDNA were cloned from the Marathon cDNA library according to the manufacturer's instructions based on the method of rapid amplification of cDNA ends (RACE) (Frohman 1990). An antisense primer (5'-AGT TATGTTCAGGAGGGTCCAGTT- $3^{\prime}$ ) and a sense primer (5'-TCGGAATCGTGGGCATCCTCATAA-3') derived from the cloned flounder cDNA fragment were used for the cloning of 5'- and 3'-regions respectively.

\section{Cloning of the fGHR gene}

Genomic DNA was prepared from the kidney of the flounder by the SDS-proteinase K method (Sambrook et al. 1989) and subjected to 30 cycles of PCR with the LA PCR kit (TAKARA). Primers were designed from the cDNA sequence to amplify each intron of the GHR gene. The primers used were as follows: primers 1 (sense) and 2 (antisense) for intron 1, primers 3 (sense) and 4 (antisense) for introns 2 and 3, primers 5 (sense) and 6 (antisense) for intron 4, primers 7 (sense) and 8 (antisense) for intron 5 , primers 9 (sense) and 10 (antisense) for intron 6, primers 11 (sense) and 12 (antisense) for intron 7, primers 13 (sense) and 14 (antisense) for intron 8, primers 15 (sense) and 16 (antisense) for intron 9. The $5^{\prime}$-flanking region of the flounder GHR gene was amplified by the inverse PCR method (Ochman et al. 1990). The kidney genomic DNA was digested with PvuII restriction enzyme (TAKARA) whose recognition site was present at $1.5 \mathrm{~kb}$ downstream of exon 1. The genomic fragments were then self-ligated with T4 DNA ligase (TAKARA) and the $5^{\prime}$-region of the flounder GHR gene was amplified by PCR with primers 17 (antisense) and 18 (sense). The amplified genomic fragments were cloned into pGEM-T Easy vector and sequenced. The locations and sequences of primers $1-18$ are shown in Fig. 1.

\section{RNase protection assay}

An RNase protection assay was performed by the previously described method (Tanaka et al. 1998). Briefly,

Figure 1 The nucleotide sequence of the flounder GHR gene. Exon and intron sequences are denoted by uppercase and lowercase letters respectively. The deduced amino acid residues are shown in the single-letter code under the exon sequences. Asterisks indicate the stop codon. The numbers above the exon sequences indicate the corresponding positions in the fGHR cDNA sequence, numbering the translation initiation position as +1 . The transmembrane domain is shown by a double underline. The box 1 motif in exon 8 and the box 2 motif in exon 9 are indicated by dotted underlines. The FGEFS motif with the replacement of E to D is underlined and the unique sequence in the 3'-truncated GHR is boxed. Positions of primers used in RT-PCR and genomic PCR are indicated by arrows above the genomic sequence. The nucleotide sequence data in this paper will appear in the EMBL/GenBank/DDBJ nucleotide databases with the accession numbers AB058418, AB058418 and AB110986. 
appropriate fragments of flounder GHR cDNA and gene were subcloned into pGEM-T Easy vector and RNA probes were synthesized using T7 or SP6 RNA polymerases and $\left[\alpha_{-}{ }^{32} \mathrm{P}\right] \mathrm{CTP}$. The RNA probes were hybridized with total RNA or poly $\mathrm{A}^{+}$RNA and digested with RNase A and RNase T1. The protected fragments of the RNA probes were separated by $6 \%$ polyacrylamide- $7 \mathrm{M}$ urea gel electrophoresis and detected by autoradiography. The intensity of the protected fragments was analyzed by a BAS1000 imaging analyzer (Fuji Photo Co., Tokyo, Japan).

\section{RT-PCR analysis}

Total RNAs prepared from tissues of the flounder were reverse transcribed into first strand cDNA using Superscript II reverse transcriptase (GIBCO BRL, Tokyo, Japan) and oligo-dT primer. The 3 '-truncated GHR cDNA was amplified by 25 cycles of PCR of $94^{\circ} \mathrm{C}$ for $40 \mathrm{~s}, 60{ }^{\circ} \mathrm{C}$ for $1 \mathrm{~min}$, and $72{ }^{\circ} \mathrm{C}$ for 3 min using primer 9 (sense) and primer 19 (antisense) (indicated in Fig. 1). The amplified cDNA fragment was electrophoresed in a $2 \%$ agarose gel and transferred to a nylon membrane. The membrane was prehybridized with yeast RNA (200 $\mu \mathrm{g} /$ $\mathrm{ml})$ in $50 \%$ formamide, $6 \times$ SSC $(1 \times$ SSC: $0 \cdot 15 \mathrm{M} \mathrm{NaCl}$, $0 \cdot 015 \mathrm{M}$ sodium citrate) and $0 \cdot 1 \% \operatorname{SDS}$ at $42{ }^{\circ} \mathrm{C}$ for $16 \mathrm{~h}$, and then hybridized with the radiolabeled GHR cDNA at $42{ }^{\circ} \mathrm{C}$ for $16 \mathrm{~h}$. After washing twice with $2 \times$ SSC containing $0 \cdot 1 \%$ SDS at $60{ }^{\circ} \mathrm{C}$ for $30 \mathrm{~min}$, the membranes were subjected to autoradiography.

\section{Results}

\section{Cloning and characterization of flounder GHR $c D N A$ and gene}

First, a $571 \mathrm{bp}$ fragment of flounder GHR cDNA was amplified by PCR from a flounder liver cDNA library using a primer pair designed from the reported sequence of turbot GHR cDNA (Calduch-Giner et al. 2001), and then the $5^{\prime}$ - and $3^{\prime}$-regions of the GHR cDNA were cloned by the RACE method. Then, the flounder GHR gene was cloned by PCR from the kidney genomic DNA using primers derived from the GHR cDNA sequence. The nucleotide sequence of the GHR gene covering the entire cDNA sequence is shown in Fig. 1. The GHR cDNA was $2339 \mathrm{bp}$ long, contained a $1926 \mathrm{bp}$ open reading frame for 641 amino acids, a $276 \mathrm{bp} 5^{\prime}$-UTR and a $138 \mathrm{bp} \mathrm{3'-}$ UTR. The GHR cDNA sequence was distributed in 10 exons and all the exon-intron junctions conformed to the GT-AG rule. The lengths of introns 1 and 2 were estimated to be approximately 9.0 and $8.0 \mathrm{~kb}$ respectively by agarose gel electrophoresis of the PCR-amplified fragments. Exon 1 contained most parts of the 5'untranslated region (272 bp out of $276 \mathrm{bp}$ ) of the GHR
cDNA, and exons 2, 4, 5, 6 and 7 encoded the extracellular domain having the common characteristics for GHR, such as six cysteine residues and the FGEFS motif with the replacement of E to D. Exon 7 encoded the transmembrane domain together with small parts of the extracellular and cytoplasmic domains. The remaining cytoplasmic domain was encoded by exons 8,9 and 10 . Box 1 and box 2 regions were observed in exons 8 and 9 respectively, and the $3^{\prime}$-UTR was encoded in exon 10.

\section{Identification of a 3'-truncated GHR $m R N A$ in the liver}

The sequence of the $3^{\prime}$-flanking region of exon 8 showed high similarity to that of the unique $3^{\prime}$-sequence of the reported 3 '-truncated variant of turbot GHR cDNA (Calduch-Giner et al. 2001). In order to examine whether the $3^{\prime}$-truncated GHR variant $(\mathrm{GHR}-\mathrm{V})$ is expressed in the liver of flounder, RT-PCR was performed with primer 1 and primer 20 derived from exon 1 and intron 8 respectively (see Fig. 1). A 1256 bp GHR cDNA fragment containing the $97 \mathrm{bp}$ sequence of the 3'-flanking region of exon 8 was amplified. The expression level of GHR-V mRNA relative to that of GHR mRNA was examined by RNase protection assay with an RNA probe derived from positions 732-1047 of GHR-V cDNA. As shown in Fig. 2, a 316-bases protected fragment derived from GHR-V mRNA was detected together with a 179-bases fragment derived from GHR mRNA. The intensity of the 179-bases fragment was 15-fold higher than that of the 316-bases fragment, indicating that GHR-V mRNA was expressed as a minor species in the liver of the flounder.

\section{Tissue distribution of GHR $m R N A s$}

The expression of GHR and GHR-V mRNAs in various tissues of the flounder was examined (Fig. 3). By RNase protection assay, GHR mRNA was detected in all the tissues examined with relatively higher levels in the liver and muscle, while GHR-V mRNA was not detectable in the RNA sample of any of the tissues (Fig. 3, upper panel). By RT-PCR analysis, GHR-V mRNA was detected in all the tissues, with higher levels in the liver and ovary, and lower levels in the brain and muscle (Fig. 3, lower panel).

\section{Cloning and characterization of the $5^{\prime}$-flanking region of the flounder GHR gene}

The 5'-flanking region of the flounder GHR gene was cloned from the genomic DNA by the inverse PCR method. Figure 4 shows the nucleotide sequence of the upstream region of the fGHR gene. In order to determine the transcriptional initiation sites of the fGHR gene in the liver, an RNase protection assay was performed with an antisense RNA probe derived from positions -562 to -193 in the GHR gene sequence, numbering the 

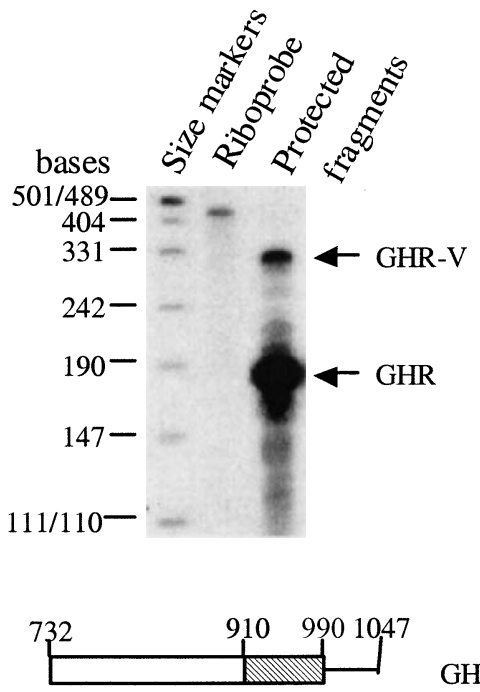

GHR-V cDNA

\section{Riboprobe}

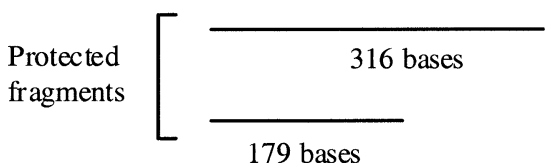

GHR-V mRNA

GHR mRNA

Figure 2 RNase protection assay of GHR and GHR-V mRNAs in the liver. Twenty micrograms poly $\mathrm{A}^{+} \mathrm{RNA}$ prepared from the liver of a female flounder were subjected to the assay. Radiolabeled Mspl digests of pUC19 plasmid DNA were used as size markers. Schematic diagrams of the riboprobe and protected fragments derived from GHR and GHR-V mRNAs are given under the autoradiogram. The hatched box indicates the unique sequence in GHR-V.

translation start site as +1 . As shown in Fig. 4, three protected fragments were detected with almost the same

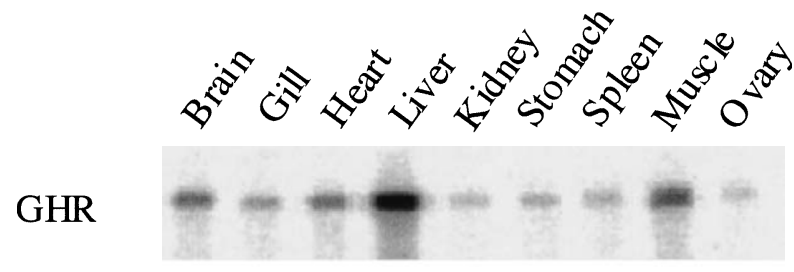

\section{GHR-V}

Figure 3 Tissue distribution of GHR and GHR-V mRNAs. (Upper panel) An RNase protection assay was performed using the same riboprobe as in Fig. 2 with $40 \mu$ g total RNA samples prepared from the tissues of a female flounder. Only the 179-bases protected fragment for GHR mRNA was detected in this assay. (Lower panel) RT-PCR was performed using primers 8 and 20 (indicated in Fig. 1) with $20 \mu \mathrm{g}$ total RNA samples prepared from the tissues of a female flounder. The $490 \mathrm{bp}$ cDNA fragment for GHR-V mRNA was detected.
-562 gtatagagaaagtgttgcagcagactgctctttccctctg -523 gcttttattttgtaggtttgtccctgcaggcttcgtctct -483 ctctcagctcatcatggagtaagagtgtattgttgccgca -443 tgagggcgcctctccgccatgtgtaacgcacacacacaca -403 cacacacacacacacacacacacacacacacacacacaca -363 cacacacacacacacacacacacacgtacacacacatagt -323 ggctcagtctcagcgaggtgotogtgtttgtgtgtgtgca -283 gtgtgtgtgtgtgtgagcagccctgaaagtacagcacggg -243 cttgatgatgaagtgagtggcagaaaagacagaaaaccgt -203 ccgtggggaagcggcgctcactcgagtcgaggtgtgggtg -163 ggcgatgtgaacaaatcctgctcggatcagatcttgtttc -123 ggggccgagcagcaggctcgaggtgagggagcaggacttt -83 tccgagcctgtcggtgctcacgctggacatcagatgacca -43 acttctgaaaagtcgatccgctcgagacatcacaacaa

Figure 4 RNase protection assay for transcription start sites and nucleotide sequence of the $5^{\prime}$-flanking region of the flounder GHR gene. (Upper panel) Nucleotide sequence of the $5^{\prime}$-flanking region of the GHR gene cloned by the inverse PCR method. The region corresponding to the riboprobe is underlined. Arrow heads indicate the positions of the transcription start sites determined by the RNase protection assay. (Lower panel) RNase protection assay with $20 \mu \mathrm{g}$ poly $\mathrm{A}^{+}$RNA prepared from the liver of a female flounder. Radiolabeled Mspl digests of pUC19 plasmid DNA were used as size markers. The arrows on the right of the lower panel show the bands of protected fragments.

intensity at positions 90,100 and 130 bases on the gel. These results indicate that the GHR mRNA is initiated with similar frequency around positions $-282,-292$, and -322 in the GHR gene.

\section{Discussion}

We have cloned and characterized the flounder GHR gene based on the cloned fGHR cDNA sequence. As shown in Fig. 5, the flounder GHR gene is composed of 10 exons similar to the human GHR gene. Exon 1 in the 


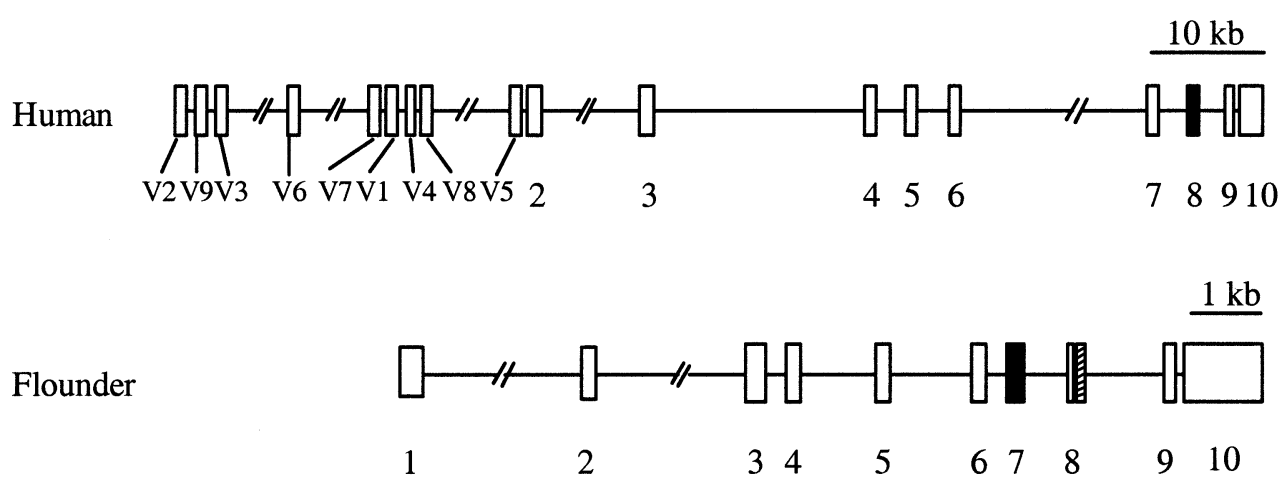

Figure 5 Comparison of the exon structures of the flounder and human GHR genes. Boxes represent exons and the horizontal lines indicate introns. A shadowed box indicates the unique region in GHR-V mRNA. Black boxes represent the exons containing transmembrane domains.

flounder gene encodes the $5^{\prime}$-UTR of the GHR mRNA, the same as exon 1 in the human GHR gene. Exons 2-6 in the flounder GHR gene encode the extracellular domain including the signal sequence in exon 2 , and exon 7 encodes the transmembrane domain. By contrast, the transmembrane region is encoded in exon 8 in the human GHR gene. No extracellular exon in the flounder GHR gene has any significant sequence similarity to any of those exons in the human GHR gene except for exon 5 which shows $62.5 \%$ overall sequence similarity to exon 6 in the human GHR gene. Among the six cysteine residues conserved in the extracellular domain, two residues exist in exon 3, and the other four in exon 4 in the flounder GHR gene. These characteristics of exons 3 and 4 in the flounder GHR gene are observed in exons 4 and 5 respectively in the human GHR gene. Consequently, no exon corresponding to exon 3 in the human GHR gene is found in the flounder GHR gene. It has been shown that the region encoded in exon 3 in the human GHR gene is not essential for GH binding (Sobrier et al. 1993, Urbanek et al. 1993, Esposito et al. 1994) and that no homologous exon is observed in the chicken GHR gene (Agawal et al. 1994). The cytoplasmic domain of the flounder GHR is encoded by three exons, 8,9 , and 10 , while the corresponding domain of the human GHR is encoded by two exons, 9 and 10. Exon 8 in the flounder GHR gene and exon 9 in the human GHR gene contain the highly conserved box 1 motif and show high sequence similarity $(70 \cdot 6 \%)$. In the human GHR gene, the remaining C-terminal part of the cytoplasmic domain and the $3^{\prime}$ UTR are encoded by exon 10, while in the flounder GHR gene, the corresponding regions are encoded in exons 9 and 10. Exon 9 in the flounder GHR gene encodes the box 2 motif and shows a significant sequence similarity $(58.9 \%)$ to the box 2 motif-containing N-terminal part of exon 10 in the human GHR gene. Exon 10 in the flounder GHR gene encodes the C-terminal part of the cytoplasmic domain together with the $3^{\prime}$-UTR, but has no significant sequence similarity to the corresponding region of exon 10 in the human GHR gene. These findings indicate the divergent process of molecular evolution between mammalian and teleost GHR genes.

In the turbot, a teleost species closely related to the flounder, a 3 '-truncated GHR mRNA containing a unique sequence at its $3^{\prime}$-end has been identified by cDNA cloning (Calduch-Giner et al. 2001). A similar GHR mRNA, GHR-V mRNA, was also identified in the flounder by RT-PCR analysis. GHR-V mRNA contains the $5^{\prime}$-end sequence of intron 8 instead of the sequence of exons 9 and 10. Although the $3^{\prime}$-end of GHR-V mRNA is not defined, the potential polyadenylation signal is observed at $272 \mathrm{bp}$ downstream from the $3^{\prime}$-end of exon 8 , suggesting that the $3^{\prime}$-truncated fGHR mRNA is generated by an alternative cleavage/ polyadenylation of the primary transcript from the GHR gene. In mouse and chicken, alternative cleavage/ polyadenylation processes generate GHBP mRNAs (Huang et al. 1993, Oldham et al. 1993, Talamantes 1994), while GHR-V mRNA in the flounder encodes a protein composed of the extracellular domain, the transmembrane domain, the box 1 region of the cytoplasmic domain and a unique C-terminal 26-amino acid sequence. Interestingly, similar structural features are observed in the short form variant of mammalian prolactin receptor (PRL-R) which is known to be generated by alternative splicing mechanisms (Kelly et al. 1991). In the mouse, the splicing of the box 1-containing exon 9 to one of the multiple exon 11s results in the generation of short form PRL-R mRNAs (Davis \& Linzer 1989). The rat short form PRL-R exhibits a dominant-negative effect on the co-expressing long form PRL-R (Perrot-Applanat et al. 1997). GHR-V mRNA is expressed in a wide range of flounder tissues, together with GHR mRNA. Although the function of GHR-V is not yet known, it might be involved in modulation of the intracellular signaling of GHR. 
In mammalian GHR genes, multiple 5'-UTR exons have been cloned and characterized, together with their 5 '-flanking regulatory regions (Edens \& Talamantes 1998, Schwartzbauer \& Menon 1998, Kopchick \& Andry 2000, Goodyer et al. 2001). Among the nine 5'-UTR exons (V1-V9) in the human GHR gene, V2, V3, V5 and V9 are expressed in a wide range of tissues, while the other five $5^{\prime}$-UTR exons are expressed only in the postnatal liver. In the flounder GHR gene, only one $5^{\prime}$-UTR exon was identified by the $5^{\prime}$-RACE analysis of the liver GHR mRNA. Although there is a possibility of the presence of other $5^{\prime}$-UTR exons in the flounder GHR gene, the identified $5^{\prime}$-UTR exon is considered to be the major one expressed in the flounder liver. The RNase protection assay showed three transcription start sites in this $5^{\prime}$-UTR exon. A 76 bp CA repeat is present immediately upstream of the most distal transcription start site, but no TATA box or other binding elements for known transcription factors are found within the $239 \mathrm{bp} 5^{\prime}$-flanking region of the GHR gene. The regulatory mechanism for the expression of the flounder GHR gene remains to be elucidated.

\section{Funding}

This work was supported by a grant (Development of Fundamental Technologies for Effective Genetic Improvement of Aquatic Organisms) from the Ministry of Agriculture, Forestry and Fisheries of Japan.

\section{References}

Agawal SK, Cogburn LA \& Burnside J 1994 Dysfunctional growth hormone receptor in a strain of sex-linked dwarf chicken: evidence for a mutation in the intracellular domain. Journal of Endocrinology 142 427-434.

Calduch-Giner J, Duval H, Chesnel F, Boeuf G, Perez-Sanchez J \& Boujard D 2001 Fish growth hormone receptor: molecular characterization of two membrane-anchored forms. Endocrinology 142 3269-3273.

Davis JA \& Linzer DI 1989 Expression of multiple forms of the prolactin receptor in mouse liver. Molecular Endocrinology 3 674-680.

Edens A \& Talamantes F 1998 Alternative processing of growth hormone receptor transcripts. Endocrine Review 19 559-582.

Edens A, Southard JN \& Talamantes F 1994 Mouse growth hormone-binding protein and growth hormone receptor transcripts are produced from a single gene by alternative splicing. Endocrinology 135 2802-2805.

Esposito N, Paterlini P, Kelly PA, Postel-Vinay MC \& Finidori J 1994 Expression of two isoforms of the human growth hormone receptor in normal liver and hepatocarcinoma. Molecular and Cellular Endocrinology 103 13-20.

Frohman MA 1990 RACE: rapid amplification of cDNA ends. In PCR Protocols, pp 28-38. Eds MA Innes, DH Gelfand, JJ Sninsky \& TJ White. San Diego, CA: Academic Press.

Godowski PJ, Leung DW, Meacham LR, Galgani JP, Hellmiss R, Keret R, Rotwein PS, Parks JS, Laron Z \& Wood WI 1989 Characterization of the human growth hormone receptor gene and demonstration of a partial gene deletion in two patients with Laron-type dwarfism. PNAS 86 8083-8087.
Goodyer CG, Zogopoulos G, Schwartzbauer G, Zheng H, Hendy GN \& Menon RK 2001 Organization and evolution of the human growth hormone receptor gene 5 '-flanking region. Endocrinology 142 1923-1934.

Huang N, Cogburn LA, Agarwal SK, Marks HL \& Burnside J 1993 Overexpression of a truncated growth hormone receptor in the sex-linked dwarf chicken: evidence for a splice mutation. Molecular Endocrinology 7 1391-1398.

Kelly PA, Djiane J, Postel-Vinay M \& Edery M 1991 The prolactin/ growth hormone receptor family. Endocrine Review 12 235-251.

Kopchick JJ \& Andry JM 2000 Growth hormone (GH), GH receptor, and signal transduction. Molecular Genetics and Metabolism 71 293-314.

Lee LT, Nong G, Chan YH, Tse DL \& Cheng CH 2001 Molecular cloning of a teleost growth hormone receptor and its functional interaction with human growth hormone. Gene 270 121-129.

Mathews LS, Norstedt G \& Palmiter RD 1986 Regulation of insulin-like growth factor I gene expression by growth hormone. PNAS 83 9343-9347.

Menon RK, Stephan DA, Singh M, Morris SM \& Zou I 1995 Cloning of the promoter-regulatory region of the murine growth hormone receptor gene. Identification of a developmentally regulated enhancer element. Journal of Biological Chemistry $\mathbf{2 7 0}$ $8851-8859$.

Menon RK, Shaufl A, Stephan DA \& Friday RP 2001 Identification and characterization of a novel transcript of the murine growth hormone receptor gene exhibiting development and tissue-specific expression. Molecular and Cellular Endocrinology 172 135-146.

Moffat JG, Dao H \& Talamantes F 2000 Alternative $5^{\prime}$-untranslated regions of mouse $\mathrm{GH}$ receptor/binding protein messenger RNA are derived from sequences adjacent to the major L2 promoter. Molecular and Cellular Endocrinology 167 147-153.

Ochman H, Medhora MM, Garza D \& Hartl DL 1990 Amplification of flanking sequences by inverse PCR. In PCR Protocols, pp 219-227. Eds MA Innes, DH Gelfand, JJ Sninsky \& TJ White. San Diego, CA: Academic Press.

Oldham ER, Bingham B \& Baumbach WR 1993 A functional polyadenylation signal is embedded in the coding region of chicken growth hormone receptor RNA. Molecular Endocrinology 7 1379-1390.

Pekhletsky RI, Chernov BK \& Rubtsov PM 1992 Variants of the 5 -untranslated sequence of human growth hormone receptor mRNA. Molecular and Cellular Endocrinology 90 103-109.

Perrot-Applanat M, Gualillo O, Pezet A, Vincent V, Edery M \& Kelly PA 1997 Dominant negative and cooperative effects of mutant forms of prolactin receptor. Molecular Endocrinology 11 $1020-1032$.

Roberts CT Jr, Brown AL, Graham DE, Seelig S, Berry S, Gabbay KH \& Rechler MM 1986 Growth hormone regulates the abundance of insulin-like growth factor I RNA in adult rat liver. Journal of Biological Chemistry 261 10025-10028.

Sambrook J, Fritsch EF \& Maniatis T 1989 Isolation of high-molecular weight DNA from mammalian cells. In Molecular Cloning, pp 9·14-9·23. Eds N Ford, C Nolan \& M Ferguson. Cold Spring Harbor, NY: Cold Spring Harbor Laboratory Press.

Schwartzbauer G \& Menon RK 1998 Regulation of growth hormone receptor gene expression. Molecular Genetics and Metabolism $\mathbf{6 3}$ 243-253.

Sobrier ML, Duquesnoy P, Duriez B, Amselem S \& Goossens M 1993 Expression and binding properties of two isoforms of the human growth hormone receptor. FEBS Letters 319 16-20.

Talamantes F 1994 The structure and regulation of expression of the mouse growth hormone receptor and binding protein. Proceedings of the Society of Experimental Biology and Medicine 206 254-256.

Tanaka M, Taniguchi T, Yamamoto I, Sakaguchi K, Yoshizato H, Ohkubo T \& Nakashima K 1998 Gene and cDNA structures of flounder insulin-like growth factor-I (IGF-I): multiple mRNA species encode a single short mature IGF-I. DNA and Cell Biology 17 859-868. 
Tse DL, Tse MC, Chan CB, Deng L, Zhang WM, Lin HR \& Cheng CH 2003 Seabream growth hormone receptor: molecular cloning and functional studies of the full-length cDNA, and tissue expression of two alternatively spliced forms. Biochimica et Biophysica Acta 1625 64-76.

Urbanek M, Russell JE, Cooke NE \& Liebhaber SA 1993 Functional characterization of the alternatively spliced, placental human growth hormone receptor. Journal of Biological Chemistry 268 19025-19032.

Zhou Y, He L \& Kopchick JJ 1994 An exon encoding the mouse growth hormone binding protein (mGHBP) carboxy terminus is located between exons 7 and 8 of the mouse growth hormone receptor gene. Receptor 4 223-227.

Zou L, Burmeister LA \& Sperling MA 1997 Isolation of a liver-specific promoter for human growth hormone receptor gene. Endocrinology 138 1771-1774.

Received 28 November 2003

Accepted 23 March 2004

Made available online as an

Accepted Preprint 29 March 2004 